\title{
The Diagnostic Value of the Patient's Reason for Encounter for Diagnosing Cancer in Primary Care
}

\author{
Kees van Boven, MD, PhD, Annemarie A. Uijen, MD, PhD, Nina van de Wiel, MD, \\ Sibo K. Oskam, PhD, Henk J. Schers, MD, PhD, and Willem J. J. Assendelft, MD, PhD
}

Purpose: Family physicians (FPs) have to recognize alarm symptoms and estimate the probability of cancer to manage these symptoms correctly. Mostly, patients start the consultation with a spontaneous statement on why they visit the doctor. This is also called the reason for encounter (RFE). It precedes the interaction and interpretation by FPs and patients. The aim of this study is to investigate the predictive value of alarm symptoms as the RFE for diagnosing cancer in primary care.

Design and setting: Retrospective cohort study in a Dutch practice-based research network (Family Medicine Network).

Method: We analyzed all patients $>45$ years of age listed in the practice-based research network, FaMe-net, in the period 1995 to 2014 (118.219 patient years). We focused on a selection of alarm symptoms as defined by the Dutch Cancer Society and Cancer Research UK. We calculated the positive predictive value (PPV) of alarm symptoms, spontaneously mentioned in the beginning of the consultation by the patient (RFE), for diagnosing cancer.

Results: The highest PPVs were found for patients spontaneously mentioning a breast lump (PPV 14.8\%), postmenopausal bleeding (PPV 3.9\%), hemoptysis (PPV 2.7\%), rectal bleeding (PPV 2.6\%), hematuria (PPV 2.2\%) and change in bowel movements (PPV 1.8\%).

Conclusion: Patients think about going to their physician and think about their first uttered statements during the consultation. In the case of cancer, the diagnostic workup during the consultation on alarm symptoms will add to the predictive value of these reasons for encounter. However, it is important to realize that the statement made by the patient entering the consultation room has a significant predictive value in itself. (J Am Board Fam Med 2017;30:806-812.)

Keywords: Cancer, Family Medicine Network (FaMe-Net), International Classification of Primary Care (ICPC), Malignancy, Primary Health Care, Symptoms

One of the most important challenges for family physicians (FPs) is to estimate the probability that a patient presenting with a particular symptom has a serious disease. ${ }^{1}$ This is especially important for cancer

This article was externally peer reviewed.

Submitted 27 February 2017; revised 12 June 2017; accepted 14 June 2017.

From the Department of Primary and Community Care, University Medical Center Radboud University, Nijmegen, The Netherlands (KvB, AAU, HJS, JJA); Student, Radboud University Nijmegen $(\mathrm{NvdW})$; Formerly of the Department of General Practice, Academic Medical Center, University of Amsterdam, Amsterdam (SKO).

Funding: none.

Conflict of interest: none declared.

Corresponding author: Kees van Boven, MD, PhD, Department of Primary and Community Care, University Medical Center Radboud University-Nijmegen, PO Box 9101, 6500 HB, Nijmegen, The Netherlands (E-mail: Kees.vanBoven@ radboudumc.nl). diagnosis, because this is preferably diagnosed at an early stage..$^{2-4}$ Generally, cancers have their first presentation in general practice, and FPs are confronted with potentially alarming symptoms on an everyday basis. Unfortunately, good estimates of the predictive value of these symptoms for cancer as reasons for encounter in primary care are largely lacking. ${ }^{5-7}$

Many cancer associations have identified socalled alarm symptoms or "red flags." ",9 These are considered key signs and symptoms of cancer, and consequently patients are advised to contact a doctor when having such an alarm symptom. These alarm symptoms may become the reason for encounter (RFE), the literal utterance of what the patient says, to contact the FP. FPs, specialists, and policy makers will benefit from knowledge of the relation between alarm symptoms as RFE in pri- 
mary care and final diagnosis, as it helps to adequately interpret these alarm symptoms at first presentation and to know how to manage these symptoms in daily practice. ${ }^{11}$ A previous primary care study concluded that new onset of 1 of 4 alarm symptoms or findings (hematuria, hemoptysis, dysphagia, and rectal bleeding) after history taking and physical examination is associated with an increased likelihood of a diagnosis of cancer, especially in men and people aged over 65 years. ${ }^{11}$ Furthermore, a recent systematic review showed that rectal bleeding or anemia should be taken as important symptoms for diagnosing colorectal cancer in primary care. ${ }^{7}$ However, those studies were based on recorded signs and symptoms after history taking and physical examination and not on the RFE/demand of care, which may better reflect the course of a patient through the health care system.

Therefore, we were interested in the value of the RFEs in relation to the diagnosis of cancer. The objective of our study is to provide more insight into the clinical relevance of presenting presumed alarm symptoms as RFE for diagnosing cancer in general practice.

\section{Method}

\section{Data Source}

We performed a retrospective cohort study using data from 1995 to 2014 generated by a practice-based research network, Family Medicine Network (FaMeNet; a fusion between the Transition Project and the Continuous Morbidity Registration). ${ }^{12,13}$ Within this network all encounters between FPs and patients are registered since 1971 . The network consists of 7 Dutch family practices (24 FPs), which routinely code each episode of care according to the International Classification of Primary Care (ICPC). ${ }^{14,15}$ An episode of care is defined as a health problem in an individual from the first encounter until the completion of the last encounter. For all episodes of care, FPs register the patient's RFE, FP's diagnosis, the certainty of the diagnosis, and FP's interventions according to the ICPC in separated fields. The RFE is the literal utterance of the reason(s) why a person enters the consultation room, translated into an ICPC code by the FP. It represents the demand for care by that person. ${ }^{10}$ The RFE should be recognized by the patient as an acceptable description of the demand of care presented by the patient.
RFE's can be presented in the form of symptoms and complaints but also as requests for prescriptions, diagnostic interventions, or as a specific diagnosis. The RFE presents the individual context of needs, expectations, and priorities around their health problems and codetermines the episode of care and FPs' responses. The validity of registration is high, as the participating FPs have regular meetings to discuss registration and use well-defined diagnostic criteria. ${ }^{1}$ The FPs are among other things trained to record the first uttered reasons for encounter. Due to suggestions of the electronic patient record and training of FP's, FPs are focused on connecting earlier episodes that might have been related to cancer. Often, this is done retrospectively, mostly when FP's receive information from hospital specialists with the certain diagnosis of cancer. On a regular basis mirror information is given to FPs about these episodes.

We extracted data of all patients aged $\geq 45$ years, resulting in approximately 7.000 listed patients per year, resulting in 118.219 patient years with 299.013 new episodes of care.

\section{Alarm Symptoms}

We analyzed all episodes of care in which the patient expressed an alarm symptom as the start of a new episode of care for contacting the FP. We focused on the alarm symptoms identified by the Dutch Cancer Society ${ }^{8}$ and Cancer Research UK. ${ }^{9}$ We converted the alarm symptoms into the corresponding ICPC codes (Table 1). This table also indicates when the ICPC code does not fully match the corresponding alarm symptom.

\section{Statistical Analysis}

First we determined the incidence of all cancers (pathologic confirmed) in our dataset. We compared the incidence data to the data from the National Cancer Institute Netherlands (2005; crude ratios) to check for representability. Then, we determined the probability of cancer in the presence of 1 of the alarm symptoms, by calculating the percentage of a (final) diagnosis of cancer in episodes starting with 1 of the alarm symptoms as RFE (positive predictive value [PPV]) or positive post-test probability. Next, we calculated the positive likelihood ratios for the cancers that occurred more than 5 times in the time period. At last, we calculated the absolute difference between the incidence (pretest probability) and the probability 
Table 1. Alarm Symptoms of the Dutch Cancer Society and Cancer Research UK and the Corresponding International Classification of Primary Care (ICPC) Code(s)

\begin{tabular}{|c|c|}
\hline Alarm Symptoms & ICPC Code \\
\hline \multirow[t]{5}{*}{ Any abnormal bleeding } & Rectal bleeding (D16) \\
\hline & Haematuria (U06) \\
\hline & Post-menopausal bleeding (X12) \\
\hline & Post-coital bleeding (X13) \\
\hline & Intermenstrual bleeding $(\mathrm{X} 08)^{*}$ \\
\hline Breathlessness & Shortness of breath/dyspnea (R02) \\
\hline Desquamationed skin & Skin texture symptom/complaint $(\mathrm{S} 21)^{*}$ \\
\hline New or changing nevus/mole & Nevus/mole (S82) \\
\hline Feeling very tired all the time & Weakness/tiredness, general (A04)* \\
\hline \multirow[t]{3}{*}{ Persistent hoarseness or cough and hemoptysis } & Hemoptysis (R24) \\
\hline & Voice symptom/complaint (R23)* \\
\hline & Cough R05 $5^{\dagger}$ \\
\hline \multirow[t]{2}{*}{ Lump } & Lump/swelling, localized (S04)* \\
\hline & Breast lump/mass female (X19) \\
\hline Nipple changes & Nipple symptom/complaint female (X20)* \\
\hline Swallowing problems & Swallowing problems (D21) \\
\hline Unexplained persistent change in bowel habits & Change in feces/bowel movements (D18) \\
\hline Unexplained weight loss & Weight loss (T08) \\
\hline \multirow[t]{4}{*}{ Urinary tract problems or changing in passing urine } & Dysuria/painful urination (U01)* \\
\hline & Urinary frequency/urgency (U02)* \\
\hline & Urinations problems, other (U05)* \\
\hline & Prostate symptom/complaint $(\mathrm{Y} 06)^{*}$ \\
\hline
\end{tabular}

*The ICPC code matches only partly with the corresponding alarm symptom.

${ }^{\dagger}$ The ICPC code is cough and not persistent cough.

having cancer given the alarm symptom (the PPV of the symptom).

\section{Results}

Incidence

Table 2 shows the incidence (pretest probability) of the most frequently occurring cancers in primary care in our database. The incidence data were comparable to the incidence data from the Dutch Cancer Institute.

\section{PPV of Cancer Presenting an Alarm Symptom}

Table 3 shows the number of alarm symptoms, the number of resulting (type of) cancers and the PPV

Table 2. Incidence (Pre-Test Probability) of Cancer in Patients $\geq 45$ years (per 1000 Patients per Year; Top 10)

\begin{tabular}{lccc}
\hline Type of Cancer (ICPC code) & ICPC Code & FaMe-Net & National CancerRegistration N1 \\
\hline Female breast* & X76 & 2.49 & 3.03 \\
Skin & S77 & 1.75 & 1.13 \\
Prostate $^{\dagger}$ & Y77 & 1.58 & 2.89 \\
Colon/rectum & D75 & 1.07 & 1.61 \\
Bronchus/lung & R84 & 0.85 & 1.26 \\
Female genital (cervix and female breast excluded) & X77 & 0.66 & 0.93 \\
Digestive (stomach, pancreas, and colon/rectum excluded) & D77 & 0.41 & 0.45 \\
Bladder & U76 & 0.28 & 0.39 \\
Stomach & D76 & 0.19 & 0.20 \\
Respiratory (bronchus/lung excluded) & R85 & 0.10 & 0.14
\end{tabular}

*Per 1000 females.

${ }^{\dagger}$ Per 1000 males.

ICPC, International Classification of Primary Care. 
Table 3. Positive Likelihood Ratios PPV in Percent of Cancer in Patients Presenting with an Alarm Symptom (1995 to 2014)

\begin{tabular}{|c|c|c|c|c|c|c|}
\hline Alarm Symptoms by ICPC & $\begin{array}{l}\text { Number of } \\
\text { RFEs }\end{array}$ & $\begin{array}{l}\text { N Resulting } \\
\text { Cancer }\end{array}$ & $\begin{array}{l}\mathrm{N}^{\ddagger} \text { Cancer } \\
\text { Overall }\end{array}$ & PPV (\%) & $\mathrm{LR}+$ & Type of Cancer $(\mathrm{N})$ \\
\hline Breast lump, female & 400 & 59 & 158 & 14.8 & 204.86 & Female breast (59) \\
\hline Postmenopausal bleeding & 385 & 15 & 42 & 3.9 & 180.69 & Female genital* $(15)$ \\
\hline Hemoptysis & 225 & 6 & 100 & 2.7 & 81.89 & Bronchus/lung (6) \\
\hline Rectal bleeding & 913 & 24 & 127 & 2.6 & 63.53 & Colon/rectum (24) \\
\hline Hematuria & 693 & 15 & 33 & 2.2 & 200.44 & Bladder (15) \\
\hline Weight loss & 866 & 18 & 410 & 2.1 & & $\begin{array}{l}\text { Colon/rectum (4), Stomach (3), } \\
\text { Bronchus/lung (3), Prostate } \\
\text { (3), Kidney (2), Pancreas (2), } \\
\text { unknown (1) }\end{array}$ \\
\hline Nipple symptom & 187 & 4 & 158 & 2.1 & & Female breast (4) \\
\hline Swallowing problems & 302 & 6 & 71 & 2.0 & & $\begin{array}{l}\text { Stomach (3), Other malignant } \\
\text { digestive neoplasm not } \\
\text { stomach/colon/pancreas (3) }\end{array}$ \\
\hline $\begin{array}{l}\text { Change in feces/bowel } \\
\text { movements }\end{array}$ & 433 & 8 & 127 & 1.8 & 44.30 & Colon/rectum (8) \\
\hline Lump/swelling localized & 6283 & 112 & 329 & 1.8 & 16.48 & Skin (112) \\
\hline Nevus/mole & 814 & 15 & 329 & 1.8 & 17.04 & Skin $(15)$ \\
\hline Prostate symptom/complaint & 343 & 3 & 87 & 0.9 & & Prostate (3) \\
\hline $\begin{array}{l}\text { Urinary frequency/urgency } \\
\text { (men) }\end{array}$ & 1007 & 6 & 87 & 0.6 & 7.70 & Prostate (6) \\
\hline Urinations problems other & 653 & 3 & 120 & 0.5 & & Prostate (2), Bladder (1) \\
\hline Voice symptom/complaint & 804 & 3 & 41 & 0.4 & & $\begin{array}{l}\text { Malignant neoplasm respiratory, } \\
\text { other (not bronchus) (2), } \\
\text { Hodgkin/lymphoma (1) }\end{array}$ \\
\hline $\begin{array}{l}\text { Skin texture } \\
\text { symptom/complaint }\end{array}$ & 716 & 3 & 329 & 0.4 & & Skin (3) \\
\hline Weakness/tiredness, general & 5454 & 18 & 327 & 0.3 & $3.46^{\dagger}$ & $\begin{array}{l}\text { Colon/rectum (8), Pancreas (3) } \\
\text { Leukemia (2), Other } \\
\text { malignant digestive neoplasm } \\
\text { (2), Hodgkin/lymphoma (1), } \\
\text { Malignant neoplasm } \\
\text { respiratory, other (not } \\
\text { bronchus) (1), Malignant } \\
\text { neoplasm genital female not } \\
\text { cervix, not breast (1), } \\
\text { Unknown (1) }\end{array}$ \\
\hline Shortness of breath/dyspnea & 4677 & 12 & 340 & 0.3 & 3.84 & $\begin{array}{l}\text { Bronchus/lung (9), Leukemia } \\
\text { (2), Hodgkin/lymphoma (1), } \\
\text { Malignant neoplasm } \\
\text { respiratory, other (not } \\
\text { bronchus) (1), Female breast } \\
\text { (1), Unknown (1) }\end{array}$ \\
\hline Cough & 13749 & 13 & 358 & 0.1 & 1.96 & $\begin{array}{l}\text { Bronchus/lung (9), Hodgkin/ } \\
\text { lymphoma (1), Other } \\
\text { malignant digestive neoplasm } \\
\text { not stomach/colon/pancreas } \\
\text { (1), Female breast (1), } \\
\text { Unknown (1) }\end{array}$ \\
\hline Dysuria & 3269 & 2 & 120 & 0.1 & & $\begin{array}{l}\text { Malignant neoplasm bladder (1), } \\
\text { Prostate (1) }\end{array}$ \\
\hline Intermenstrual bleeding & 134 & 0 & & & & \\
\hline Postcoital bleeding & 59 & 0 & & & & \\
\hline
\end{tabular}

*Malignant neoplasm of uterus.

${ }^{\dagger}$ For colon cancer.

${ }^{\ddagger}$ Overall number of all types of cancer on the same row.

ICPC, International Classification of Primary Care; LR, likelihood ration; PPV, positive predictive value; RFE, reason for encounter. 
per 100 patients per year in patients presenting with an alarm symptom. Moreover, the positive likelihood ratios are presented; For 11 alarm symptoms as RFE (and corresponding ICPC codes) the probability for cancer as final diagnosis was $\geq 1$ per 100 patients. The highest probabilities for cancer were found in patients presenting with a breast lump (14.8\%) and postmenopausal bleeding (3.9\%). This means, for example, that $14.8 \%$ of the female patients aged $\geq 45$ years presenting with a breast lump will be diagnosed with cancer. The lowest probabilities were found in patients presenting with intermenstrual bleeding and postcoital bleeding. It also means that from all cases with breast cancer 37\% (59/158) did present themselves with lump in the breast as RFE.

Highest differences between the pretest (incidence) and post-test probability (combining the results from tables 2 and 3) were found in cancers starting with a breast lump (increasing from 2.5 to 148 per 1000 patient years) and postmenopausal bleeding (from 0.7 to 39 per 1000 patients). Lowest scores were found in cancers starting with cough (the probability to have bronchus cancer does hardly change, from 0.9 to 1 per 1000 patient years) and urinary frequency/urgency (the probability to have prostate cancer increased from 1.6 to 6 per 1000 patient years).

\section{Discussion}

Our study provides insight into the PPV of alarm symptoms presented as RFE in diagnosing cancer in primary care. We found that most of the generally known alarm symptoms were associated with an increased probability of a cancer diagnosis. High PPVs were found in patients with a breast lump $(\mathrm{PPV}=14.8 \%)$, postmenopausal bleeding $(\mathrm{PPV}=$ $3.9 \%)$, hemoptysis $(\mathrm{PPV}=2.7 \%)$, rectal bleeding $(\mathrm{PPV}=2.6 \%)$, hematuria $(\mathrm{PPV}=2.2 \%)$, and change in bowel movements $(\mathrm{PPV}=1.8 \%)$. Large differences between the pretest and post-test probability were found in cancers starting with a breast lump (increasing from 2.5 to 148 per 1000 patient years) and postmenopausal bleeding (from 0.7 to 39 per 1000 patient years).

\section{Comparison with Other Studies}

The incidence figures in our study are similar to a large-scale representative national study in the UK. ${ }^{16}$ Jones and colleagues ${ }^{11}$ found, in the same age groups as we, higher PPV for rectal bleeding and colorectal cancer (3.4\% compared with $2.6 \%$ in our study) and for hematuria and bladder cancer (7.3\% compared with $2.2 \%$ in our study). The differences in PPVs are most likely due to the fact that we used the RFE (the entrance complaint as expressed by the patient) and not signs and symptoms registered by the FP. The RFE is a different concept than the presence or absence of an alarm symptom, and we think that knowledge about the RFE adds important information. Knowing the RFE will direct the diagnostic process in the clinical encounter. In line with our results, the metaanalysis performed by Astin and colleagues ${ }^{7}$ found that rectal bleeding is an important first sign of colorectal cancer. Barton ${ }^{17}$ reported from a retrospective cohort study in women from 40 to 69 years a PPV of $11 \%$ for breast lump and breast cancer, in line with our results $(\mathrm{PPV}=14.8 \%)$. Parker et $\mathrm{al}^{18}$ analyzed the relation between postmenopausal bleeding and endometrial cancer and found a PPV of $0.3 \%$ in women aged 45 to 54 years and $5.4 \%$ in those aged 75 to 84 years. Our numbers were too low to make a further age stratification, but overall (women $\geq 45$ years old) our PPV of $3.9 \%$ is in line with this study.

\section{Strengths and Limitations}

One of the strengths of this study is that the data have been extracted from a long-lasting reliable registration network. It is the only existing database where FPs register RFE, diagnosis, and interventions for all episodes of care. We know that our patient cohort is representative for general practices across The Netherlands and various other countries. $^{16,19}$

By showing the absolute differences between pretest probability and post-test probability we can better clarify the relation between alarm symptom and cancer, taking into account the incidence of cancers in primary care. Displaying the alarm symptoms as RFE emphasizes the importance of patients' spontaneous expressed reasons to contact the FP for diagnosing cancer. A limitation of the study is that some alarm symptoms did not correspond to the ICPC codes available, for instance persistent cough. For the alarm symptom, "urinary tract problems or changing in passing urine," we found 4 available ICPC codes. In our study we calculated the post-test probabilities of single RFEs and not for combinations of RFEs. For combining 
multiple RFEs a larger dataset is needed. Another limitation is that our sample size was too small for more detailed probability calculations, for example stratified by sex or age categories. Moreover, it is possible that we have missed a few diagnoses that were made after the end of 2014, while symptoms already existed. Because the dataset was extracted 12 months after the end of 2014, we consider this chance very small.

\section{Implications for Clinical Practice}

Based on pretest and post-test probabilities, we found that breast lump and postmenopausal bleeding are the alarm symptoms with the highest clinical relevance when presented as RFE. This high clinical relevance justifies prompt diagnostic followup by the FP or quick referral to a specialized clinic when a patient $\geq 45$ years of age presents with a breast lump or postmenopausal bleeding.

The alarm symptom hemoptysis has a slightly lower clinical relevance. Consequently, when a patient presents with hemoptysis, FPs have to take into account patient's age, other symptoms, clinical features, medical history and familial history to decide whether to refer or not. This also applies to other alarm symptoms such as rectal bleeding, hematuria, weight loss, nipple symptoms, swallowing problems, change in feces/bowel movements, lump/swelling, and nevus/mole. Banks et $\mathrm{al}^{20}$ found that even at a $1 \%$ risk that a symptom might indicate cancer, a large majority of patients (87\%) chose for further diagnostic testing.

The clinical relevance for alarm symptoms as RFE, such as urinary frequency/urgency and shortness of breath, for cancer is very low.

The alarm symptoms weight loss and weakness/ tiredness result in cancers of different origin, which makes it necessary for a FP not to limit diagnostics to 1 organ system.

With our study we emphasize the importance of incorporating the RFE, defined as the patient's spontaneous expressed reasons to contact the FP, in the diagnostic algorithms for diagnosing cancer.

\section{Conclusion}

Although a lot is already known on predictive value of symptoms and combinations of symptoms, we think that the RFE adds to our knowledge base. $\mathrm{RFE}$ is a different concept than the (combination of) symptom(s). The diagnostic workup during the consultation seems to add only little to the stated RFE by the patient. We think that this observation is both relevant and novel. Patients think about going to their physician and think about their first statements during the consultation. This statement has a predictive value in itself. Our results provide new and applicable insight in the diagnostic value of the RFEs for diagnosing cancer in general practice. We found that the alarm symptoms breast lump and postmenopausal bleeding justify prompt diagnostic followup by the FP or a quick referral to a specialized clinic. For other alarm symptoms, FPs have to take into account other factors in history taking and physical examination, such as patient's age, other symptoms, clinical features, medical history, and familial history.

This study would not have been possible without the participation of the Transition Project doctors: P. H. Dijksterhuis, MD, $\mathrm{PhD}$, Wirdum and Olst; A. Groen, MD, Amstelveen; J. A. de Haan, MD, Franeker; A. M. Honselaar-De Groot, MD, Amstelveen; D. Janssen, MD, Franeker; T. A. L. Polman, MD, Franeker; G. O. Polderman, MD, Amstelveen; K. E. I. Stolp, MD, Amstelveen; N. Valken, MD, Wirdum; Amstelveen; M. T. M. Veltman, MD, PhD. (deceased), Amstelveen; M. Woerdeman, MD, Amstelveen.

To see this article online, please go to: http://jabfm.org/content/ 30/6/806. full.

\section{References}

1. Lamberts H, Oskam SK, Okkes IM. The clinical relationship between symptoms and the final diagnosis in general practice, determined by means of posterior probabilities calculated on the basis of the Transition Project. Nederlands Tijdschrift Voor Geneeskunde 2005;149:2566-72.

2. Hamilton W. Cancer diagnosis in primary care. Br J Gen Pract 2010;60:121-128.

3. Mulka O. NICE suspected cancer guidelines. Br J Gen Pract 2005;55:580-581.

4. Lyratzopoulos G, Wardle J, Rubin G. Rethinking diagnostic delay in cancer: How difficult is the diagnosis? BMJ 2014;349:g7400.

5. Jones R, Rubin G, Hungin P. Is the two week rule for cancer referrals working? BMJ 2001;322:15551556.

6. Ford AC, Veldhuyzen van Zanten SJ, Rodgers CC, et al. Diagnostic utility of alarm features for colorectal cancer: Systematic review and meta-analysis. Gut 2008;57:1545-1553.

7. Astin M, Griffin T, Neal RD, et al. The diagnostic value of symptoms for colorectal cancer in primary care: A systematic review. Br J Gen Pract 2011; 61(586):e231-e243. 
8. Kanker.nl. Symptomen van kanker. Available from: https://www.kanker.nl/bibliotheek/artikelen/794symptomen-van-kanker. Accessed June 29, 2015.

9. Cancer Research UK. Key signs and symptoms of cancer. Available from: http://www.cancerresearchuk. org/about-cancer/cancer-symptoms, Accessed June 29, 2015.

10. Bentzen N. Family medicine research: implications for Wonca. Ann Fam Med 2004;2(Suppl 2):S45-S49.

11. Jones R, Latinovic R, Charlton J, Gulliford MC. Alarm symptoms in early diagnosis of cancer in primary care: Cohort study using General Practice Research Database. BMJ 2007;334:1040.

12. Okkes I, Oskam S, Van Boven K, et al. EFP. Episodes of care in Dutch Family Practice. Epidemiological data based on the routine use of the International Classification of Primary Care (ICPC) in the Transition Project of the Academic Medical Center/ University of Amsterdam (1985-2003). In: Okkes IM, Oskam SK, Lamberts H. ICPC in the Amsterdam Transition Project. CD-Rom Amsterdam, The Netherlands: Academic Medical Center/University of Amsterdam, Department of Family Medicine, 2005.

13. Van Weel C. The Continuous Morbidity Registration Nijmegen: Background and history of a Dutch general practice database. Eur J Gen Pract 2008; 14(Suppl 1):5-12.

14. Lamberts H, Hofmans-Okkes I. Episode of care: A core concept in family practice. J Fam Pract 1996; 42:161-167.
15. WONCA International Classification Committee. International Classification for Primary Care, Second Edition (ICPC-2). Oxford, UK: Oxford University Press, 1998.

16. van der Linden MW, Westert GP, Bakker de D, et al. Tweede Nationale Studie naar ziekten en verrichtingen in de huisartspraktijk: klachten en aandoeningen in de bevolking en in de huisartspraktijk. Utrecht, The Netherlands: NIVEL, 2004.

17. Barton MB, Elmore JG, Fletcher SW. Breast symptoms among women enrolled in a health maintenance organization: Frequency, evaluation, and outcome. Ann Intern Med 1999;130:651-657.

18. Parker C, Hippisley-Cox J, Coupland C, et al. Rectal and postmenopausal bleeding: Consultation and referral of patients with and without severe mental health problems. Br J Gen Pract 2007;57: 371-376.

19. Soler JK, Okkes I, Oskam S, et al. An international comparative family medicine study of the Transition Project data from the Netherlands, Malta and Serbia. Is family medicine an international discipline? Comparing incidence and prevalence rates of reasons for encounter and diagnostic titles of episodes of care across populations. Fam Pract 2012;29:283-298.

20. Banks J, Hollinghurst S, Bigwood L, et al. Preferences for cancer investigation: A vignette-based study of primary-care attendees. Lancet Oncol 2014; $15: 232-240$. 